DOI: $10.34185 / 1991-7848.2018 .01 .07$

УДК 621.74.045:[669.3+669.356]:621.78

В.Ф. Мазорчук, С.И. Репях, К.И. Узлов, А.В. Дзюбина

\title{
ВЛИЯНИЕ СТРУКТУРЫ ЛИТОЙ МЕДИ И БРОНЗ НА ЗНАЧЕНИЕ ИХ КОЭФФИЦИЕНТА ТЕРМИЧЕСКОГО ЛИНЕЙНОГО РАСШИРЕНИЯ
}

\begin{abstract}
Величина коэффициента термического линейного расширения, в основном, зависит от температуры и фазового состава материала, формирование которого определяется не только химическим составом отливки, но и условиями её затвердевания. Задача исследований определение влияния условий затвердевания металлов и сплавов на величину их КТЛР в области упругого состояния литой меди и её сплавов. В настоящей работе исследованы медь технической чистоты по ГОСТ 859-2001, безоловянные по ГОСТ 18175-78, ГОСТ 493-79 и оловянная бронзы по ГОСТ 613-79. Установлено, что при охлаждении в литейной форме температура перехода из пластичного в упругое состояние у меди технической чистоты составляет $286^{\circ} \mathrm{C}$, у бронзы БрА5 $426^{\circ} \mathrm{C}$, у бронзы БрА9ЖЗЛ $\sim 359^{\circ} \mathrm{C}$, у бронзы БрО5Ц5С $\sim 312^{\circ} \mathrm{C}$. Определены величины коэффициентов линейного расширения меди и её некоторых сплавов. Различие величин коэффициентов термического линейного расширения меди и её сплавов, затвердевших в условиях свободной и абсолютно затруднённой линейной усадки, обусловлено различиями морфологии и пространственной ориентации образующихся кристаллов, долей фазовых и структурных составляющих, а также дефектов кристаллической структуры в сплаве.

Ключевые слова: медь, бронза, сплав, усадка, микроструктура, зерно, затвердевание, расплав, кокиль
\end{abstract}

\section{Состояние вопроса}

Коэффициент термического линейного расширения (КТЛР) любого материала параметр во многом предопределяющий значительное число свойств любого изделия, его технологичность, надёжность, долговечность и т.п. Величина КТЛР, в основном, зависит от температуры и фазового состава материала, формирование которого определяется не только химическим составом отливки, но и условиями её затвердевания.

Данный параметр является фундаментальной характеристикой любого материала. Тем не менее, данные о КТЛР литых металлов и сплавов в настоящее время носят фрагментарный характер. Поэтому работа, направленная на определение КТЛР литой меди и её сплавов, является актуальной.

\section{Задача исследований}

Задача исследований - определение влияния условий затвердевания металлов и сплавов на величину их КТЛР в области упругого состояния литой меди и её сплавов.

\section{Основные результаты исследований}

Коэффициенты свободной и абсолютно затруднённой линейной усадки, а также величину КТЛР определяли на медных и бронзовых отливках цилиндрической формы ( $\varnothing 16 \times 80$ мм), затвердевших и охлаждённых в условиях свободной и абсолютно затруднённой линейной усадки. Испытуемые отливки изготавливали путём заливки расплава в стальные кокили с гладкой и рифленой цилиндрической поверхностью без защитного покрытия.

Для плавки меди и бронз использовали шихтовые материалы технической чистоты. Плавки меди и её сплавов проводили в графитовом тигле индукционной печи металлоёмкостью 2 кг (по меди). Температура перегрева расплавов во всех случаях составляла $100 \pm 10{ }^{\circ} \mathrm{C}$. Плавку вели под слоем древесного угля с последующим “дразнением” расплава и его раскислением фосфористой медью. Заливку кокилей осуществляли непосредственно из плавильного тигля. Температура кокилей в момент их заливки расплавами составляла $200 \pm 20$ ${ }^{0} \mathrm{C}$. Заливку расплавов испытуемых материалов осуществляли через прибыль со стороны верхнего торца образца.

(c) Мазорчук В.Ф., Репях С.И., Узлов К.И., Дзюбина А.В., 2018 
Изготовление отливок-образцов осуществляли по методике [1, 2]. Зависимости КТЛР металлов и сплавов, залитых в кокиль, от температуры определяли на образцах, которые затвердевали и охлаждались: в условиях свободной линейной усадки (группа 1), в условиях абсолютно затруднённой линейной усадки (группа 2).

По результатам измерений длин образцов рассчитывали значения свободной $\left(\alpha_{c}\right)$ и абсолютно затруднённой $\left(\alpha_{A 3}\right)$ линейных усадок. По результатам дилатометрических испытаний для каждого из образцов рассчитывали зависимости относительного изменения его KTЛP $\left(\mathrm{k}_{\mathrm{t}}\right)$ от температуры и температуру перехода материала отливки из пластичного в упругое состояние ( $\left.\mathrm{t}_{п \mathbf{y}}\right)$, используя следующие формулы [3]:

$$
\begin{gathered}
k_{t}=\frac{a_{t}}{t-20}=k_{f}+D \cdot t+E \cdot t^{2}, \\
t_{\pi y}=\frac{a_{A 3}}{k_{f}+D \cdot t_{\mathrm{MV}}+E \cdot t_{\mathrm{W}}^{2}}+t_{20},
\end{gathered}
$$

где $\mathrm{t}$ - температура образца; $\mathrm{k}_{\mathrm{f}}, \mathrm{D}, \mathrm{E}$ - эмпирические коэффициенты; $\mathrm{t}_{20}=20^{\circ} \mathrm{C}$.

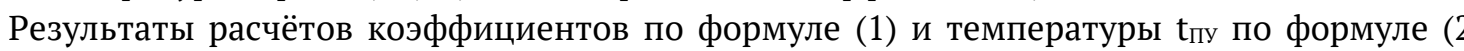
для меди и некоторых марок бронз приведены в таблице 1.

Таблица 1

Коэффициенты свободной $\left(\alpha_{C}\right)$ и абсолютно затруднённой $\left(\alpha_{\mathrm{A} 3}\right)$ линейных усадок, $\mathrm{k}_{\mathrm{f}}, \mathrm{D}, \mathrm{E}$ и

\begin{tabular}{|c|c|c|c|c|c|c|c|}
\hline $\begin{array}{l}\text { Металл, сплав } \\
\text { (интервал температур, }{ }^{0} \mathrm{C} \text { ) }\end{array}$ & $\begin{array}{l}\text { Вид } \\
\text { усадки }\end{array}$ & $\mathrm{k}_{\mathrm{f}} \cdot 10^{6}$ & $\mathrm{D} \cdot 10^{12}$ & $\mathrm{E} \cdot 10^{12}$ & $\begin{array}{l}\alpha_{c}, \\
\%\end{array}$ & $\begin{array}{l}\alpha_{\mathrm{A} 3} \\
\%\end{array}$ & $\begin{array}{l}\mathrm{t}_{\Pi \mathrm{y}} \\
{ }^{0} \mathrm{C}\end{array}$ \\
\hline \multirow{2}{*}{$\mathrm{Cu}(20 \ldots 500)[4]$} & свободная & 16,63 & \multirow{2}{*}{3532} & \multirow{2}{*}{1,62} & 2,31 & & \multirow{2}{*}{286} \\
\hline & абс. затр. & 16,13 & & & & 0,46 & \\
\hline \multirow{2}{*}{ БрА5 (20 ... 500) [5] } & свободная & 15,28 & \multirow{2}{*}{3633} & \multirow{2}{*}{1,25} & 2,31 & & \multirow{2}{*}{426} \\
\hline & абс. затр. & 13,00 & & & & 0,60 & \\
\hline \multirow{2}{*}{ БрА9Ж3Л (20 ... 500) [6] } & свободная & 16,92 & \multirow{2}{*}{3937} & \multirow{2}{*}{0,31} & 2,31 & & \multirow{2}{*}{359} \\
\hline & абс. затр. & 14,47 & & & & 0,54 & \\
\hline \multirow{2}{*}{ БрО5Ц5С5 (20 ... 500) [7] } & свободная & 18,21 & \multirow{2}{*}{6000} & \multirow{2}{*}{0,85} & 1,67 & & \multirow{2}{*}{312} \\
\hline & абс. затр. & 17,21 & & & & 0,59 & \\
\hline
\end{tabular}

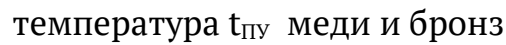

Примечание: абс. затр. - абсолютно затруднённая линейная усадка Зависимости $\mathrm{k}=\mathrm{f}(\mathrm{t})$ представлены на рисунках 1 и 2.

В исследованиях также использовали образцы (отливки) меди, отожжённые в течение часа при $620 \pm 10{ }^{\circ} \mathrm{C}$, а также образцы, отожжённые в течение часа при $620 \pm 10{ }^{\circ} \mathrm{C}$ и впоследствии нагартованные.

Результаты исследований этих образцов представлены на рисунке 2, где обозначения соответствуют медным образцам, которые характеризуются: 1 - свободной линейной усадкой при охлаждении; 2 - свободной линейной усадкой при охлаждении и последующим отжигом; 3 - свободной линейной усадкой при охлаждении, последующим отжигом и нагартовкой; 4 абсолютно затруднённой линейной усадкой; 5 - абсолютно затруднённой линейной усадкой и последующий отжигом; 6 - абсолютно затруднённой линейной усадкой, последующим отжигом и нагартовкой.

Анализ зависимостей на рисунках 1 и 2 показывает, что величины КТЛР меди и бронз, затвердевших и охлаждённых в условиях свободной линейной усадки $\left(\mathrm{k}_{\mathrm{c}}\right)$, больше, чем у затвердевших и охлаждённых в условиях абсолютно затруднённой линейной усадки $\left(\mathrm{k}_{\mathrm{A} 3}\right)$. Идентичность характера изменения величин КТЛР испытуемых материалов от температуры (см. рисунок 1) свидетельствует о том, что разница между значениями величин $\mathrm{k}_{\mathrm{C}}$ и $\mathrm{k}_{\mathrm{A} 3}$ обусловлена не только определённым различием структуры таких образцов, но и наличием в ней дефектов, число которых, по-видимому, тем больше, чем больше степень затруднённости линейной усадки затвердевающего и охлаждающегося металла (сплава). 

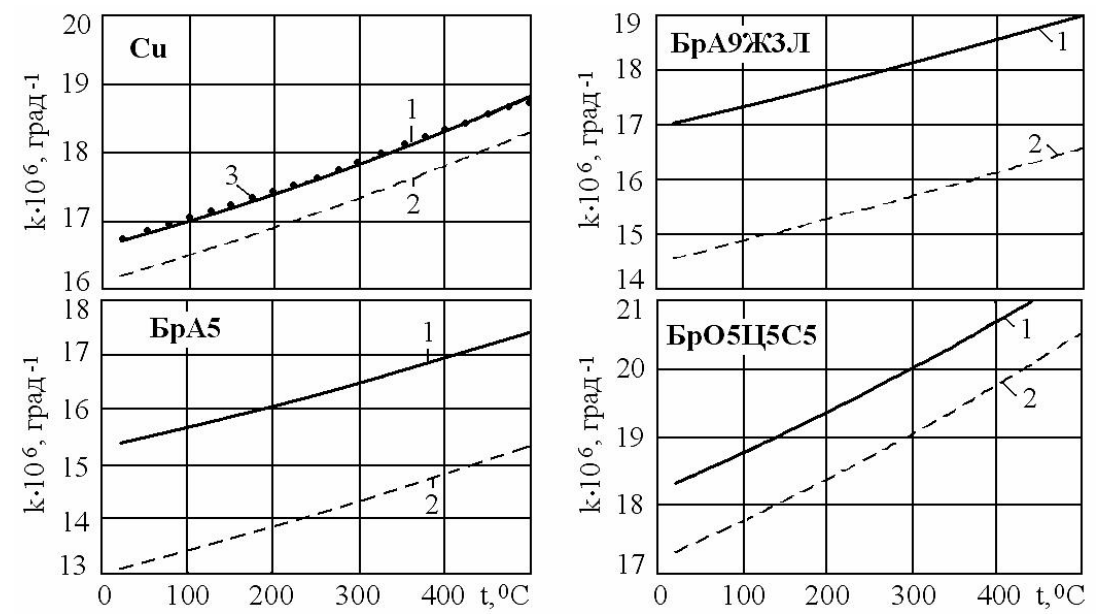

Рисунок 1 - Зависимости КТЛР образцов металлов и сплавов технической чистоты, залитых в кокиль, от температуры: 1 - образец группы 1; 2 - образец группы 2; 3 - данные [3]

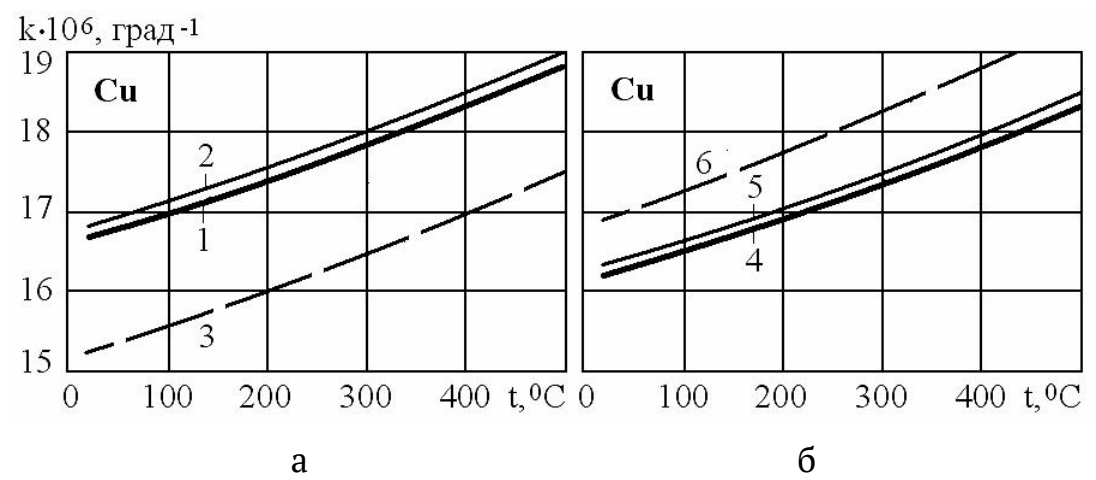

Рисунок 2 - Зависимости КТЛР от температуры литой меди, затвердевшей и охладившейся в условиях свободной (а) и абсолютно затруднённой (б) линейных усадок

Кроме степени дефектности кристаллического строения, причиной изменения величины КТЛР для одного и того же материала является также изменение его структурного состояния. В частности, макроструктура меди (см. рисунок 3,a), затвердевшей в кокиле в условиях свободной линейной усадки, представлена относительно большими равноосными зернами твердого раствора кислорода в меди. При затвердевании меди в кокиле в условиях абсолютно затрудненной линейной усадки ее зерно измельчается в связи с более высокой интенсивностью теплоотвода такой формы от расплава (см. рисунок 3,б).

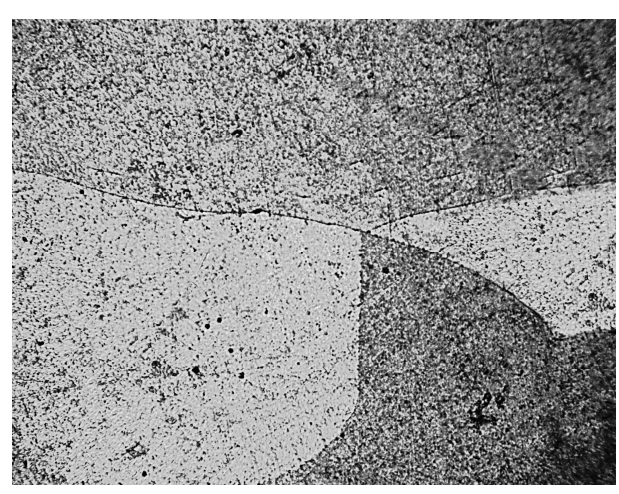

a

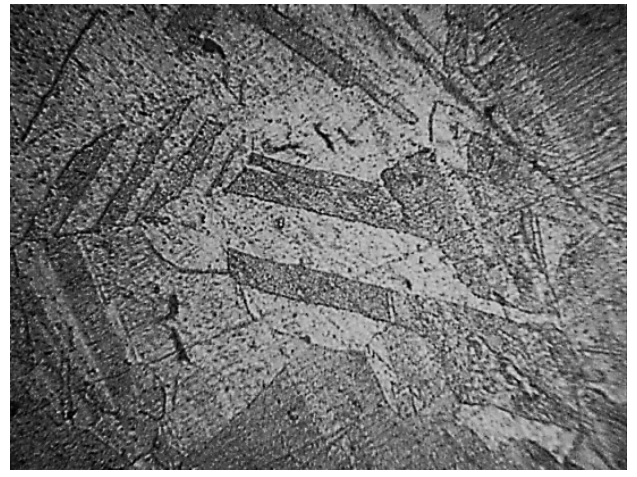

б

Рисунок 3 - Микроструктуры (×1000) отливок из меди марки М1, охлажденных в условиях свободной (а) и абсолютно затрудненной линейных усадок (б) 
Отжиг меди не приводит к изменению её структуры, но способствует определённому увеличению величины её КТЛР (см. рисунок 2).

В случае нагартовки предварительно отожжённых образцов меди, независимо от условий изготовления, в их структуре зёренные полиэдры фрагментируются - появляются двойники и полосы скольжения, что следует из анализа рисунка 4.

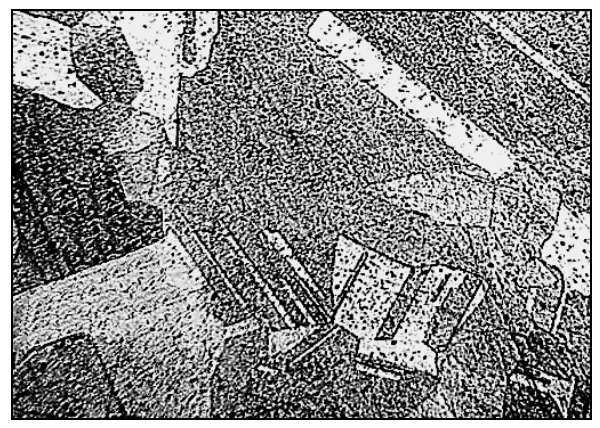

a

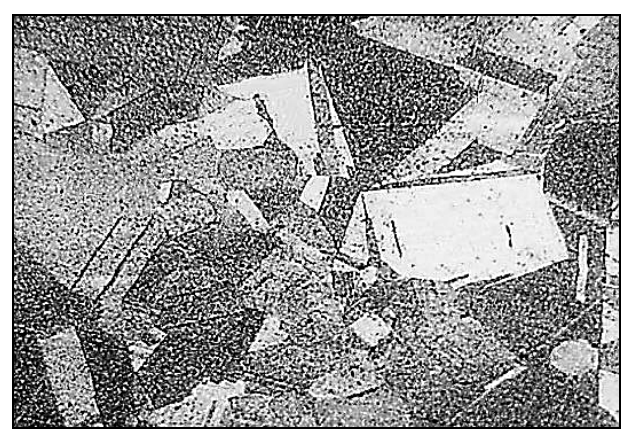

б

Рисунок 4 - Микроструктуры (×300) кокильных отливок из меди в нагартованном состоянии, охлажденных в условиях свободной (а) и абсолютно затрудненной линейных усадок (б)

При этом, у образцов, сформированных в условиях свободной линейной усадки, величина КТЛР понижается, а у образцов, сформированных в условиях абсолютно затруднённой линейной усадки - повышается, что, по-видимому, обусловлено резким изменением количества структурных дефектов в нагартованных образцах.

$\mathrm{B}$ соответствии с фазовой диаграммой $\mathrm{Cu}-\mathrm{Al}$ [8] структура бронзы с содержанием $\mathrm{Al}<9,4 \%$ (по массе) является однофазной и состоит из кристаллов $\alpha$-Cu ( $\alpha$-раствор $\mathrm{Al}$ в $\mathrm{Cu}$ ). Учитывая существенную разницу температур плавления меди и алюминия, закономерно предполагать появление в структуре такой бронзы внутрикристаллической ликвации. Действительно, на шлифах бронзы БрА5 травлением в растворе $\mathrm{CuCl}_{2}$ в водном растворе аммиака выявляется типичная структура неоднородного твердого раствора (рис. 5) - дендриты меди и междуветвия, обогащённые алюминием (см. рисунок 5).

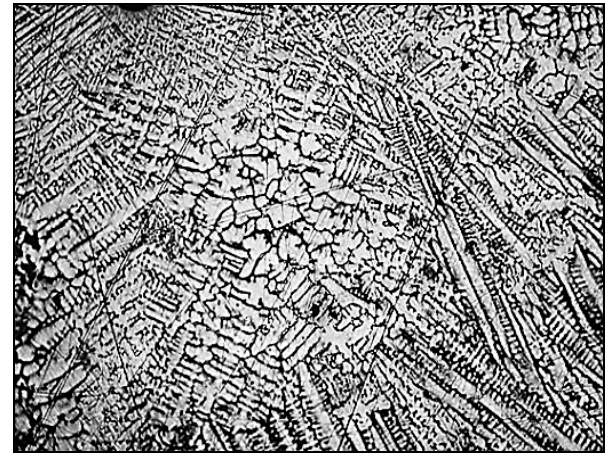

a

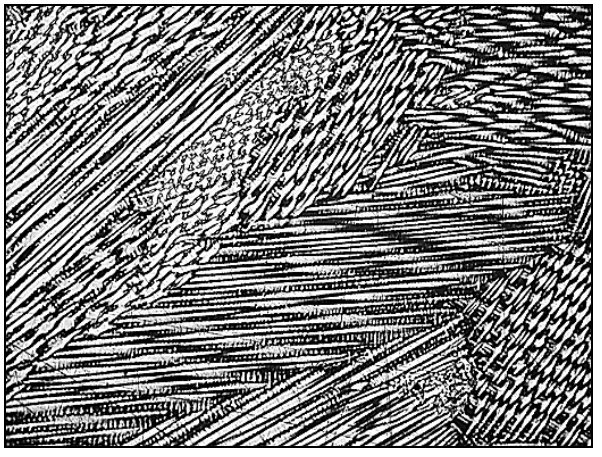

6

Рисунок 5 - Микроструктуры (×100) кокильных отливок из бронзы БрА5, охлажденных в условиях свободной (а) и абсолютно затрудненной (б) линейных усадок

Степень дендритной ликвации и размер субзеренных дендритов неоднородного твердого раствора зависят от скорости охлаждения при затвердевании. При этом, увеличение интенсивности теплоотвода от кристаллизующегося расплава усиливает ликвацию и измельчает дендриты литого материала $[9,10]$. Результаты сравнительного анализа микроструктур (см. рисунок 5) однозначно свидетельствуют об измельчении размеров осей дендритов $\alpha-\mathrm{Cu}$ твердого раствора и об увеличении степени внутрикристаллической ликвации при использовании абсолютно затрудненной линейной усадки (см. рисунок 5,б) в сравнении с аналогичной структурой отливок, охлажденных в условиях свободной усадки (см. рисунок 5 ,a). 
То есть, в данном случае, изменение условий и интенсивности теплоотвода от кристаллизующихся расплавов бронзы БрА5 приводит к изменению их субзеренной структуры, что, по-видимому, и обусловливает различие величин их КТЛР (см. рисунок 1).

В бронзах БрО5Ц5С5 и БрА9ЖЗЛ изменение условий и интенсивности теплоотвода от кристаллизующихся расплавов обусловили измельчения структурных составляющих и, соответственно, изменение величин их КТЛР.

На рисунке 6 предоставлены микроструктуры бронзы БрО5Ц5С5, которая кристаллизовалась, соответственно, в условиях свободной и абсолютно затрудненной линейных усадок.

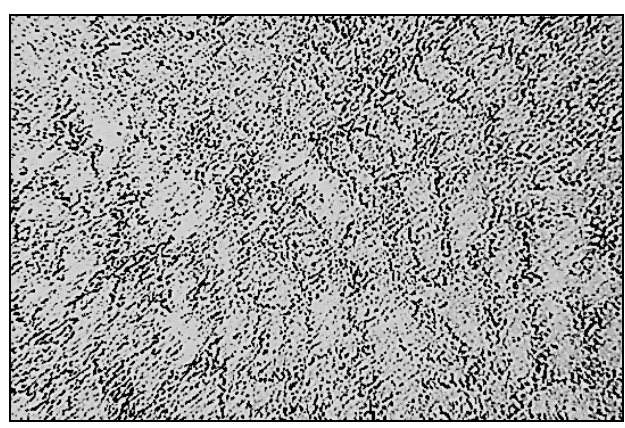

a

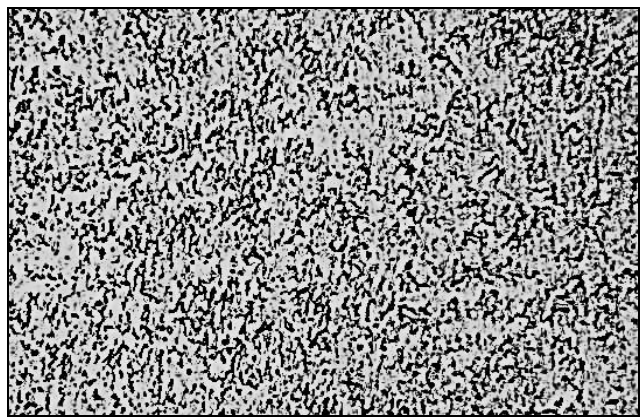

6

Рисунок 6 - Микроструктуры (×300) кокильных отливок из бронзы БрО5Ц5С5, охлажденных в условиях свободной (а) и абсолютно затрудненной (б) линейных усадок

В данном случае другая совокупность фазовых равновесий системы $\mathrm{Cu}-\mathrm{Sn}$ (предел растворимости $\mathrm{Sn}$ в $\mathrm{Cu}$ - до $10 \%$, по массе), обуславливает специфический характер структурообразования сплава с формированием первичных кристаллов $\alpha-\mathrm{Cu}$ (в данном случае $\alpha$-раствор - это раствор Sn и Zn в Cu) дендритной морфологии, эвтектоида $(\alpha+\beta)$ и кристаллов $\mathrm{Pb}$. При этом в одном случае размер дендритов фазы $\alpha$-Cu существенно больше, чем во втором случае. Соответственно, количество эвтектоидной структурной составляющей в бронзе БрО5Ц5С5, затвердевшей в условиях абсолютно затрудненной линейной усадки (см. рисунок 6,б), значительно больше, чем у бронзы, затвердевшей в условиях свободной линейной усадки (рисунок 6,a).

В бронзе БрА9ЖЗЛ совокупность фазовых равновесий системы $\mathrm{Cu}-\mathrm{Al}$ (предел растворимости $\mathrm{Al}$ в $\mathrm{Cu}$ составляет 10\%, по массе), обусловливает такой характер структурообразования: микроструктура бронзы состоит из первичных светлых кристаллов $\alpha$ $\mathrm{Cu}$ (в данном случае $\alpha$-раствор - это раствор $\mathrm{Al}$ и $\mathrm{Fe}$ в $\mathrm{Cu}$ ), эвтектоида $\left(\alpha+\gamma_{2}\right)$ и тёмных кристаллов железистой составляющей, вероятно - $\mathrm{FeAl}_{3}$, дендритной морфологи равномерно распределённых по всему объёму сплава. Причём, в одном случае размер дендритов фазы $\alpha$-Cu существенно больший (см. рисунок 7 ,a), чем во втором случае (см. рисунок 7,6 ).

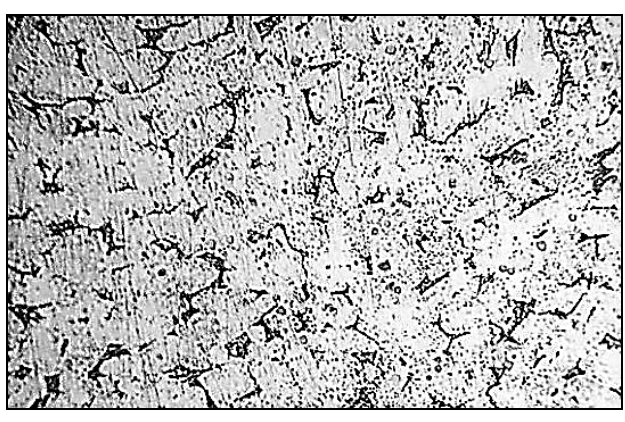

a

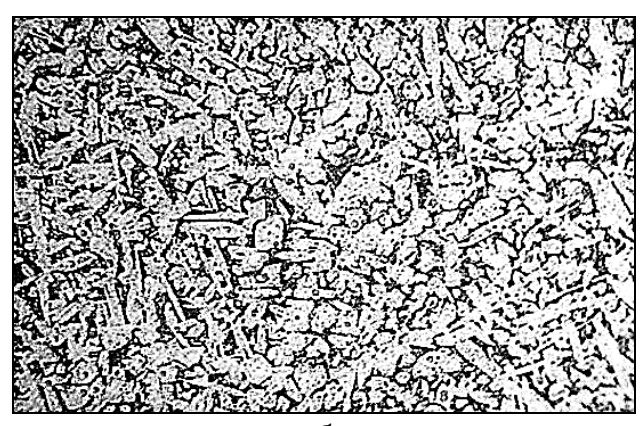

6

Рисунок 7 - Микроструктуры (×300) кокильных отливок из бронзы БрА9Ж3Л, охлажденных в условиях свободной (а) и абсолютно затрудненной (б) линейных усадок 
Соответственно, количество эвтектоидной составляющей в структуре бронзы, затвердевшей в условиях абсолютно затрудненной линейной усадки (см. рисунок 7,б) значительно превышает соответствующий показатель БрА9ЖЗЛ, которая кристаллизовалась в условиях свободной линейной усадки (см. рисунок 7,a).

Причиной описанного выше структурного многообразия в исследуемых образцах является разница в скорости кристаллизации их расплавов, которая, по результатам термографирования, выше в 2,8 ... 3,1 раза в образцах, которые затвердевали в условиях абсолютно затрудненной линейной усадки. Эта закономерность обеспечивается благодаря рифлению поверхности кокиля, который был использован для изготовления данных образцов.

\section{Выводы}

1. Результаты исследований настоящего исследования свидетельствуют о том, что при охлаждении в литейной форме, температура перехода из пластичного в упругое состояние меди технической чистоты составляет $286^{\circ} \mathrm{C}$., у бронзы БрА $5 \sim 426^{\circ} \mathrm{C}$, у бронзы БрА9Ж3Л 359 ${ }^{\circ} \mathrm{C}$, у бронзы БрО5Ц5С $\sim 312{ }^{\circ} \mathrm{C}$.

2. Различие величин коэффициентов термического линейного расширения меди и её сплавов, затвердевших в условиях свободной и абсолютно затруднённой линейной усадки, обусловлено различиями морфологии и пространственной ориентации образующихся кристаллов, а также долей фаз и дефектов кристаллической структуры в сплаве.

\section{ЛИТЕРАТУРА}

1. Ливарні властивості металів і сплавів для прецизійного лиття: підручник для вищих учбових закладів. / В.О. Богуслаєв, С.І. Реп'ях, В.Г. Могилатенко, 3.А. Івченко та ін.; під ред. C.I. Реп'яха та В.Г. Могилатенка; 2-е вид., доп. та доопр. - Запоріжжя: АТ “МОТОР СIЧ”, 2016. -474 c.

2. Мазорчук В. Ф. Коэффициенты термического линейного расширения литого олова, алюминия и сплава АЛ2 / В.Ф. Мазорчук, К. И. Узлов, С. И. Репях, А.В. Дзюбина. - Теория и практика металлургии, 2017, № 3-4 (110-111). - С. 125-128.

3. Казанцев Е. И. Промышленные печи: справ. рук. для расч. и проект. / Е. И. Казанцев; 2-е изд., перераб. и доп. - М.: Металлургия, 1975. - 368 с.

4. ГОСТ 859-2001 Медь. Марки

5. ГОСТ 18175-78 Бронзы безоловянные, обрабатываемые давлением. Марки.

6. ГОСТ 493-79 Бронзы безоловянные литейные. Марки.

7. ГОСТ 613-79 Бронзы оловянные литейные. Марки.

8. ASM Metals Handbook. Volume 03: Alloy Phase Diagrams / ASM International. - Режим доступу: http://www.asminternational.org/search/journal_content/56/10192/25871543/PUBLICATION

9. Бунин К.П. Металлография /К. П. Бунин, А. А. Баранов.- М.: Металлургия, 1970.- 256с.

10. Лейбензон В.О. Тверднення металів і металевих композицій / В.О. Лейбензон, В.Л. Пілюшенко, В.М. Кондратенко та ін.. - Київ: Наукова думка, 2009. - 446с.

\section{REFERENCES}

1. LivarnI vlastivostI metalIv i splavIv dlya pretsizIynogo littya: pIdruchnik dlya vischih uchbovih zakladIv. / V.O. BoguslaEv, S.I. Rep'yah, V.G. Mogilatenko, Z.A. Ivchenko ta In.; pId red. S.I. Rep'yaha ta V.G. Mogilatenka; 2-e vid., dop. ta doopr. - ZaporIzhzhya: AT “MOTOR SICh”, 2016. - 474 s. 
2. Mazorchuk V. F. Koeffitsientyi termicheskogo lineynogo rasshireniya litogo olova, alyuminiya i splava AL2 / V.F. Mazorchuk, K. I. Uzlov, S. I. Repyah, A.V. Dzyubina. - Teoriya i praktika metallurgii, 2017, \# 3-4 (110-111). - S. 125-128.

3. Kazantsev E. I. Promyishlennyie pechi: sprav. ruk. dlya rasch. i proekt. / E. I. Kazantsev; 2-e izd., pererab. i dop. - M.: Metallurgiya, 1975. - 368 s.

4. GOST 859-2001 Med. Marki

5. GOST 18175-78 Bronzyi bezolovyannyie, obrabatyivaemyie davleniem. Marki.

6. GOST 493-79 Bronzyi bezolovyannyie liteynyie. Marki.

7. GOST 613-79 Bronzyi olovyannyie liteynyie. Marki.

8. ASM Metals Handbook. Volume 03: Alloy Phase Diagrams / ASM International. - Rezhim dostupu: http://www.asminternational.org/search/journal_content/56/10192/25871543/PUBLICATION

9. Bunin K.P. Metallografiya /K. P. Bunin, A. A. Baranov.- M.: Metallurgiya, 1970.- 256s.

10. Leybenzon V.O. Tverdnennya metalIv I metalevih kompozitsIy / V.O. Leybenzon, V.L. PIlyushenko, V.M. Kondratenko ta In.. - KiYiv: Naukova dumka, 2009. - 446s.

Received 31.01.18

\section{EFFECT OF CAST COPPER AND BRONZE STRUCTURE ON THE VALUE OF THEIR THERMAL EXPANSION COEFFICIENT}

The magnitude of the coefficient of thermal linear expansion mainly depends on the temperature and phase composition of the material, the formation of which is determined not only by the chemical composition of the casting, but also by the conditions of its solidification. The objective of the research is to determine the influence of the solidification conditions of metals and alloys on the magnitude of their CTLR in the field of the elastic state of cast copper and its alloys. Research task of this work was to determine the influence of metals and alloys solidification conditions on the value of their CTLE in elastic state region of cast copper and its alloys. Results of these study investigations indicate that during cooling in casting mold temperature transition of technical purity copper from plastic to elastic state is $2860 \mathrm{C}$. Accordingly, these values in bronzes: BrA5 $\sim 426^{\circ} \mathrm{C}, \mathrm{BrA9Zh} 3 \mathrm{~L}$ $\sim 359^{\circ} \mathrm{C}$, BrO5Z5S5 $312^{\circ} \mathrm{C}$. Variation in the values of thermal linear expansion coefficients of copper and its alloys which solidified under conditions of free and absolutely hindered linear shrinkage is due to differences in morphology and spatial orientation of crystals formed in alloys, as well as the fractional phases' composition and defectiveness of the crystal structure.

Keywords: Copper, bronze, alloy, shrinkage, microstructure, grain, solidification, melt, chill mold.

\section{ВПЛИВ СТРУКТУРИ ЛИТОЇ МІДІ ТА БРОНЗ НА ЗНАЧЕННЯ ЇХ КОЕФІЦІЄНТУ ТЕРМІЧНОГО ЛІНІЙНОГО РОЗШИРЕННЯ}

Завдання досліджень було визначення впливу умов твердіння металів та сплавів на величину їх КТЛР в області пружного стану литої міді та ї̈ сплавів. Результати досліджень наявної роботи свідчать про те, що при охолодженні в ливарній формі температура переходу 3 пластичного до пружного стану міді технічної чистоти складає $286^{\circ} \mathrm{C}$, у бронзи БрА $\sim 426^{\circ} \mathrm{C}$, у бронзи БрА9Ж3Л $~ 359{ }^{\circ} \mathrm{C}$, у бронзи БрО5Ц5С5 $312{ }^{\circ} \mathrm{C}$. Різниця величин коефіцієнтів термічного лінійного розширення міді та іiі сплавів, які затверділи в умовах вільної та абсолютно затрудненної лінійної усадки, обумовлена різницею морфології та просторової орієнтації кристалів, що формуються, а також часток фаз та дефектів кристалічної структури в сплаві.

Ключові слова: мідь, бронза, сплав, усадка, мікроструктура, зерно, твердіння, розплав, кокіль. 
Мазорчук Владимир Фёдорович - к.т.н., доцент, кафедра литейного производства, Национальная металлургическая академия Украины.

Mazorchuk Vladimir - Ph.D., Associate Professor, Department of Foundry, National Metallurgical Academy of Ukraine.

Репях Сергей Иванович - д.т.н., с.н.с., Национальная металлургическая академия Украины.

Repykh Sergey - Doctor of Engineering Sciences, Senior Researcher, National Metallurgical Academy of Ukraine.

Узлов Константин Иванович - д.т.н., професор, Национальная металлургическая академия Украины.

Uzlov Konstantin - Doctor of Technical Sciences, Professor, National Metallurgical Academy of Ukraine.

Дзюбина Алина Валентиновна - аспирант, Национальная металлургическая академия Украины.

Dzyubina Alina - Postgraduate Student, National Metallurgical Academy of Ukraine. 